\title{
Financing Risks in the Development of Urbanization in \\ China -- Based on the Perspective of Rural Land Property Right Mortgage Financing
}

\author{
Jiao Yin ${ }^{1,2,3}$, Hongmei Zhang ${ }^{1,2,3}$ \\ ${ }^{1}$ Guizhou Institution for Technology Innovation and Entrepreneurship Investment, Guizhou University of Finance \\ and Economics, Guiyang Guizhou 550025, China \\ ${ }^{2}$ Guizhou Institution for Urban Economy and Development, Guizhou University of Finance and Economics, Guiyang \\ Guizhou 550025, China \\ ${ }^{3}$ School of Finance, , Guizhou University of Finance and Economics, Guiyang Guizhou 550025, China
}

\section{我国城镇化发展中融资风险研究二基于农村土地产权 抵押融资角度 \\ 殷娇 ${ }^{1,2,3}$, 张红梅 $1,2,3$ \\ 1贵州财经大学贵州科技创新创业投资研究院，贵州贵阳 550025，中国 \\ 2贵州财经大学贵州城镇经济与发展研究院, 贵州贵阳 550025, 中国 \\ 3 贵州财经大学金融学院, 贵州贵阳 550025, 中国}

\begin{abstract}
At present, China's urbanization is in a stage of rapid development. In the promotion of urbanization development and the integration of urban and rural areas, it's becoming crucial to solve the problems of the rural finance. As a new way of financing, the land finance has caused widespread attention. This paper has analyzed the potential risk of land financing in the view of land property mortgage financing. This paper has done risk analysis mainly from the aspect of market, finance, business, law, etc. and put forward some suggestions of legislation improvement, establishing professional land assessment agencies, erecting sound risk compensation mechanisms for prevention and control measures to crack financing difficulties in the urbanization.
\end{abstract}

Keywords: Land property right; Land finance; Financing.

\section{摘要}

目前我国城镇化正处于快速发展阶段, 在推进城镇化 发展、促进城乡一体化的过程中, 破解农村融资问题 变得至关重要。土地融资作为一种新的融资方式引起 广泛的关注, 本文选取土地产权抵押融资这一全新视 角来分析目前土地融资的潜在风险。本文主要从市场、 金融、经营、法律等方面进行风险分析, 并提出完善 立法、建立专业农地评估机构、健全风险补偿机制等 防控措施以破解城镇化中的融资困境。

关键词: 土地产权; 土地融资; 融资风险

一、引言

近十几年里, 中央一号文件曾多次提到 “三农” 问 题, 我国是农业大国, “三农” 问题与我国农业经济 发展息息相关, 为了促进农村经济发展、推进城乡 一体化, 我国根据国情大力开展农村城镇化工作。 改革开放以来, 随着工业化的进步, 我国的城镇化 呈现一种起点低、速度快的发展趋势。1978 年我国 的城镇化率仅为 $17.92 \%$, 而 2015 年的城镇化率高 达 $56.10 \%$, 提高了 38 个百分点, 37 年里我国城镇 化高速发展。在 “十二五” 时期, 我国每年城镇人 
口增加 2000 万人, 城镇化率年均提高 1.23 个百分 点。国家发改委副主任胡祖才曾在今年 1 月份国务 院新闻办举行的国务院政策例行吹风会上表示 “城 镇化规划提出, 到 2020 年户籍人口城镇化率要达到 $45 \%$, 常住人口城镇化率 $60 \%$ 左右。”

伴随着城镇化的快速发展, 也出现了越来越多 的问题。当前各地区地理位置、经济基础、资源环 境方面的差异性导致我国城镇化发展的不均衡。表 1 中列举了部分地区城镇化率的数据, 通过比较可 知, 东部地区的城镇化率一般在 $60 \%$ 以上, 其中北 京、上海、天津三大城市已经处于高度城镇化的阶 段, 它们的城市化率高达 $80 \%$ 以上, 中部地区的城 镇化率大多在 $50 \%$ 以上, 而西部地区的城镇化水平 相对偏低, 大约在 $40 \%$ 以上。与东、中部地区相比, 西部地区的城镇化发展相对滞后。

\begin{tabular}{cccccc} 
& \multicolumn{2}{c}{ 表 1} & 2015 & 年部分地区城镇化率 \\
\hline \multicolumn{2}{c}{ 东部 } & \multicolumn{2}{c}{ 中部 } & \multicolumn{2}{c}{ 西部 } \\
\hline 上海 & $89.12 \%$ & 安徽 & $50.50 \%$ & 四川 & $47.69 \%$ \\
北京 & $86.51 \%$ & 江西 & $51.62 \%$ & 贵州 & $42.01 \%$ \\
天津 & $82.64 \%$ & 湖北 & $56.85 \%$ & 云南 & $42.90 \%$ \\
广东 & $68.71 \%$ & 湖南 & $50.50 \%$ & 甘肃 & $43.19 \%$ \\
江苏 & $66.52 \%$ & 山西 & $55.03 \%$ & 新疆 & $47.25 \%$ \\
\hline
\end{tabular}

此外，在推进农村城镇化的进程中，融资问题 也引起了广泛的关注。农村融资是农村金融的重要 组成部分, 我国许多专家学者对城镇化中的融资问 题也做了深入的研究, 财政部科学研究所课题组 (2013) $)^{\mathbf{1} 11}$ 对我国城镇化进程中地方政府融资问题 进行过课题研究, 研究表明目前我国的传统融资面

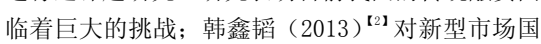
家城镇化建设中的融资机制做过详细的研究; 葛扬、 朱七 (2013) ${ }^{\mathbf{I} 31}$ 曾提过 “在我国转型特定的政治经济 体制下, 土地作为一种稀缺资源, 成为政府融资的 重要方式” 并对土地融资模式进行了相关研究。研 究表明, 在我国城镇化高速发展的今天, 传统的融 资方式已经陷入困境, 土地融资作为一种新的融资 方式, 在实践中备受关注。本文主要基于土地产权 抵押融资这一全新视角对我国土地融资进行风险研 究, 寻找其防控措施, 解决当前农村城镇化中融资 困难的问题。

\section{二、我国城镇化发展中的土地融资现状}

改革开放初期, 政府的金融支持是我国推行城镇化 的主要资金来源。农村城镇化进程中, 基础设施建
设、劳动力转移、农业结构调整等方面都需要大量 的资金支持, 如果仅仅靠政府部门的财政支持是远 远不够的。面对资金需求量的与日俱增, 我们需要 更多的融资渠道来解决目前资金匮乏的问题。政府 财政拨款、地方债券、银行贷款、民间借贷等都是 我国传统的融资方式, 随着城镇化进程的推进和农 村经济的迅速发展, 土地融资也已经成为城镇化快 速发展中不可或缺的融资手段。土地是农业发展的 基础, 对国计民生起到至关重要的作用。根据财政 部公布的统计数据显示, 2015 年土地增值税为 3832 亿元, 耕地占用税达到 2097 亿元, 城镇土地使用税 高达 2142 亿元。在有偿使用土地的制度下, 土地的 流转给地方政府带来了大量的资金收入。

农村土地产权抵押融资是盘活农村土地资源、 解决城镇化发展中农民资金融通困难、改善农民生 活生产方式的重要融资方式 ${ }^{[4 \mathbf{1}}$ 。本文中我国土地产 权抵押主要是指农村宅基地使用权抵押和土地承包 经营权抵押。

1、农村宅基地使用权抵押融资

农业的快速发展对资金的需求日益增加, 农村 居民资金来源有限，抵押物也十分蒉乏，这也是农 村融资陷入困境的原因之一，农村宅基的抵押给融 资开辟了一条新的路径。农村宅基地使用权抵押是 目前国内农户筹资常见的贷款手段, 《物权法》中 规定, “宅基地使用权人依法对集体所有的土地享 有占有和使用的权利, 有权依法利用该土地建造住 宅及其附属设施”。我国现由法律中对集体土地使 用权有严格的限制, 宅基地是禁止被抵押的, 但是 在实践中，允许农村宅基地使用权抵押，是集体土 地使用权物权化的要求。2 010 年《关于全面推进农 村金融产品和服务方式创新意见》银发文件中要求 明确开展农村土地宅基地使用权抵押业务, 探索开 展抵押贷款试点, 2013 年《中共中央关于全面深化 改革若干重大问题的决定》中也强调了要进一步明 确农民更多的财产权利, 保障农户宅基地用益物权, 推进农民住房财产权抵押试点 ${ }^{\mathbf{5} \mathbf{1}}$ 。

福建晋江市从上世纪 90 年代中期开始办理农 民住房抵押业务, 晋江是全国 15 个宅基地制度改革 的试点之一, 也是全国农房抵押贷款试点县（市、 区）。截止到 2015 年年末, 晋江全市农房抵押贷款 余额为 5.34 亿元, 户数 643 户, 累计发放 30 亿元, 受惠群众超过 1 万户。2015 年, 第十二届全国人大 常务委员会第十八次会议决定, 授权国务院在北京 市大兴区等 232 个试点县 (市、区) 行政区域, 其中包 括天津市蓟县等 59 个试点县 (市、区) 行政区域暂时 调整实施《物权法》《担保法》关于集体所有的宅 
Risk Analysis and Crisis Response in Big Data Era (RAC-16)

基地使用权不得抵押的规定 ${ }^{661}$ 。目前我国现有的宅 基地使用权抵押模式有金融机构直接抵押、政府或 公司等第三方担保抵押、共同担保抵押、间接抵押 及隐形抵押等不同模式，农村宅基地使用权抵押的 相关业务正在逐步推行中, 将在实践中不断完善。

2、土地承包经营权抵押融资

土地承包经营权是在我国农村土地承包经营制 度下产生的一种特殊的土地权利, 是一项用益物权。 土地承包经营权抵押一般是指土地承包经营权人在 法律许可的范围内, 在不转移土地占有的情况下, 将土地承包经营权作为债权的担保, 当债务人不履 行债务时, 债权人有权依法处分该土地承包经营权 并对处分所得价款优先受偿 ${ }^{[7]}$ 。

我国早在 1988 年于贵州涺潭县进行了土地承 包经营权抵押融资的试点工作, 在政府部门的支持 下, 涺潭县成立了土地金融公司, 承包经营者可通 过抵押土地承包经营权获得贷款 ${ }^{[81}$ 。之后又在宁夏、 山东、湖北、四川等多个省进行试点, 然后在全国 各个地区逐步推进。每个地区根据区域特点选取的 土地承包经营权抵押模式不同，其中宁夏同心县实 行的是 “农户+土地协会+金融机构” 模式, 山东寿 光市采用 “农户+村委会+金融机构”, 山东菄庄市 采用 “农户+土地合作社+金融机构” 模式, 湖北天 门市采用 “农户+行业协会” 和 “农户+农业担保公 司”两种融资模式等。

其中, 山东杳庄市在 2008 年开始开展土地产权 制度和农业经营体系内的改革, 2011 年颁布《本庄 市农村土地使用权经营收益权质押贷款管理暂行办 法》, 2012 年政府出资成立了担保公司, 为土地承 包经营权抵押贷款提供担保, 2013 年建立市级农村 产权交易市场 ${ }^{191}$ 。截止到 2014 年 7 月, 疋庄市农 民土地承包经营确权面积达到 151.58 万亩, 乡镇产 权交易所数量达到 60 家, 农村产权交易总额为 10.18 亿元, 进场交易土地面积为 60.46 万亩, 累 计土地承包经营权抵押贷款金额超过 5 亿元, 其中 单笔最大贷款金额为 1000 万元。土地承包经营权抵 押业务开始逐渐被农民接受。

目前我国一些地区已经建立了土地融资平台, 随着土地产权融资业务在全国范围内开展, 农村土 地产权抵押的潜在风险日益突出。

\section{三、土地产权抵押融资的潜在风险}

农民是否能够按期偿还贷款是整个土地融资的核心 风险, 针对我国土地产权抵押融资的实际情况, 我
们可以将其潜在风险分为市场风险、金融风险、经 营风险、法律风险。

\section{1、市场风险}

在进行土地产权抵押融资时, 首先要面对的就 是土地市场风险。目前我国的土地产权抵押正处于 试点阶段, 并不成熟, 土地抵押市场也不完善, 监 管力量薄弱, 缺乏咨询、公证等相关的中介服务机 构。其次, 在农村地区, 正规的农村土地评估机构 数量很少, 不能提供专业的土地评估服务。合理评 估在农村土地融资过程中扮演不可或缺的角色, 其 评估机构的满乏将给土地市场带来一定的风险。目 前我国缺少与市场价格协调的农村土地定价基准和 评估制度, 无法真实准确的反映土地供求情况, 造 成信息不对称, 又缺少监管机制的约束, 造成土地 评估不规范, 出现了很多高估土地以获取高额评估 费用的事件，增加了土地融资的潜在风险。我国的 土地市场还存在土地投机、开发成本等不稳定因素, 容易造成农产品价格的大幅度波动, 存在一定不可 预期的市场风险, 这些因素都制约了土地抵押业务 的推广。

\section{2、金融风险}

金融机构在土地产权抵押交易活动中出现的金 融风险主要包括操作风险、信用风险、担保风险等。 在抵押土地产权时要严格依照相关规定进行登记操 作, 需要依法办理相关的登记手续, 才能让土地产 权抵押合同生效。但是目前农户对土地登记操作认 识不足, 加大了土地产权抵押融资的操作风险。信 用风险是指受信人不能履行还本付息的责任而给授 信人造成一定的经济损失的风险, 目前我国农村土 地融资信用风险较高。民借贷还贷的意识薄弱, 信 用等级差, 这些都导致不良贷款的不断增加。2015 年四季度末，我国商业银行不良贷款余额超过了一 万亿元, 不良贷款率达到 $1.67 \%$, 其中与农业发展 紧密相关的农业银行和农商行是整个不良贷款率不 断攀升的主要风险点。目前, 作为一种新型的影子 银行的某些地方融资平台, 也存在较高的信用风险 ${ }^{\mathbb{1} 101}$ 。另外银行、农信社等金融机构在办理土地产权 抵押贷款业务时, 对抵押人信息及农业生产经营活 动缺乏了解, 信息不对称, 容易发生欺诈事件, 金 融机构要承担一定经济损失风险。金融机构不健全 的信贷管理程序、担保机构的匮乏, 导致土地融资 过程中必须面临操作风险、担保风险等。

\section{3、经营风险}

我国是一个多种自然灾害频繁发生、灾害分布 地域广阔、灾害损失较为严重的国家。根据表 2 中 近十一年的数据可知, 自然灾害对我国农业影响很 
Risk Analysis and Crisis Response in Big Data Era (RAC-16)

大，每年的农作物受灾面积都高达几千万公顷，直 接造成的经济损失额非常高。虽然最近几年我国农 业经济发展迅速, 2015 年我国农村居民人均可支配 收入首次超过 11000 元大关, 但是农产品的价格还 受市场价格的影响, 农业收入受到一定的限制, 面 对频繁发生的自然灾害, 农户个体、合作组织等在 生产经营中的抗灾能力有限。而且我国当前的农业 保险投保率较低, 这大大增加了农业经营收益的不 确定性, 提高了土地产权抵押业务的风险系数。此 外, 在生产经营中运用现代化技术可以增加农产品 产量, 优化资源配置, 避免资源浪费, 减小经营风 险, 但目前我国农村的生产技术水平仍有待提高, 尤其是西部地区农业技术水平偏低, 这会给农业经 营管理带来很大的压力。

表 2 2005-2014 年全国自然灾害损失情况

\begin{tabular}{c|c|c|c}
\hline \multirow{2}{*}{ 年份 } & $\begin{array}{c}\text { 农作物受灾面积合计 } \\
\text { (万公顷 ) }\end{array}$ & $\begin{array}{c}\text { 直接经济损失 } \\
\text { ( 亿元 ) }\end{array}$ \\
\cline { 2 - 3 } & 受灾 & 绝收 & \\
\hline 2005 & 3881.8 & 459.7 & 2042.0 \\
2006 & 4109.1 & 540.9 & 2528.1 \\
2007 & 4899.3 & 574.7 & 2363.0 \\
2008 & 3999.0 & 403.2 & 11752.4 \\
2009 & 4721.4 & 491.8 & 2523.7 \\
2010 & 3742.6 & 486.3 & 5339.9 \\
2011 & 3247.1 & 289.2 & 3096.4 \\
2012 & 2496.2 & 182.6 & 4185.5 \\
2013 & 3135.0 & 384.4 & 5808.4 \\
2014 & 2489.1 & 309.0 & 3373.8 \\
2015 & 2177.0 & 223.3 & 2704.1 \\
\hline
\end{tabular}

数据来源: 中国统计年鉴

\section{4、法律风险}

土地产权抵押融资需要政府部门的财政支持和 法律支持。目前我国土地抵押融资正处于初级阶段, 不够成熟, 现有的法律法规都不完善, 对土地产权 抵押有严格的限制，农村土地产权抵押的合法性问 题亟待解决, 否则一旦发生土地产权抵押纠纷, 将 会给金融机构带来一定的经济损失风险。

通过以上分析, 我们可以认识到土地产权抵押 融资的风险主要来源于法律法规的不完善、土地评 估机构的不规范、土地信息不对称、农业担保机构 匮乏等。为了大力推广土地产权抵押融资业务、破 解农村融资困境、促进农村城镇化的发展, 我国相 关政府部门必须采取有效措施对土地产权抵押融资 进行风险防控。

\section{四、土地产权抵押融资风险的防控措施}

1、完善土地融资方面的立法

我国的土地产权抵押业务目前大多处于试点阶 段, 但是当前的《物权法》、《担保法》等法律法 规中还没有作相应的调整, 相关政府部门应该根据 土地产权抵押的实践情况及时对相关法律法规做调 整，减少对宅基地使用权抵押和土地承包经营权抵 押的诸多限制, 完善土地融资方面的立法, 为开发 土地产权市场的潜在能力提供法律保障。

2、建立农村土地产权专业评估机构

土地产权抵押贷款额受到抵押物价值的限制, 公正合理的评估土地是土地融资的关键之一, 针对 目前我国土地市场的情况, 我们需要建立一个专业 的土地产权评估机构, 这个评估机构必须是独立的 第三方, 提高机构内工作人员的服务素质, 规范土 地评估行为, 做到公平公正, 增加其公信力。

3、加快农村信用体系建设

信用风险是土地抵押融资中的主要风险之一, 我国目前的农村信用体系并不完善, 农户还贷意识 薄弱, 贷款信用度较差, 针对这种情况, 我国应该 加快农村信用体系建设。首先, 要完善农户信用档 案建设, 使得在办理土地产权抵押贷款前金融机构 可以在一定程度上了解农户以往的信用情况。其次, 政府可以和金融机构合作在农村建立信用村、信用 县等试点, 为农村土地产权抵押贷款提供一个良好 的信用环境。

4、健全风险补偿机制

相关政府部门应该加大对金融机构的财政支持, 以激励金融机构为农户提供更多土地产权抵押贷款 业务。由于土地产权抵押融资存在着潜在的风险, 为了规避风险, 金融机构对土地抵押贷款业务有一 定的限制。为了保障土地抵押贷款业务的开展, 政 府部门可以健全风险补偿机制, 首先要设立风险补 偿准备金, 当农户贷款违约数量达到一定比例时, 用风险准备金来弥补金融机构的一部分经济损失。 其次, 要成立土地产权抵押贷款担保机构, 并探索 更多元化的担保模式，例如基金担保、公司担保、 经营户担保等等不同的方式。此外, 我们可以选择 在经常通过土地产权抵押方式进行融资的地区, 增 加关于土地产权抵押融资方面的保险服务, 降低当 地金融机构不良贷款的风险，激励当地金融机构扩 大土地产权抵押贷款业务的范围。

5、加快土地产权信息数据库的建设

为了让金融机构可以真实的了解抵押土地的信 息, 有效规避由于信息不对称造成的潜在风险, 我 
Risk Analysis and Crisis Response in Big Data Era (RAC-16)

们需要建立一个完整的农村土地产权数据库。通过 网络技术和现有的数据库, 利用调研等方式, 将土 地确权情况和登记情况等相关数据一一纳入土地产 权数据库, 形成易查阅的电子档案。我们还要拓展 土地数据库的系统功能, 加入新的土地产权抵押业 务信息系统, 健全土地产权抵押登记系统, 给农户 和金融机构提供信息查询、业务咨询等一些列的服 务, 使双方可以及时了解土地产权的抵押状态, 避 免陷入土地纠纷, 这样可以有效规避因为信息不对 称导致的融资风险, 同时也促进土地融资业务的快 速发展。

\section{五、结束语}

我国的城镇化发展已经取得了一定的成就, 面对如 此快速的发展, 传统的融资手段受到很大的冲击, 土地产权抵押融资作为一种新的融资手段应运而生, 已经在全国多个地区进行实践。随着试点地区数量 的增加、实践力度的增强, 土地产权抵押融资的潜 在风险也日益突出。本文分别市场、金融、经营、 法律四个方面分析潜在风险及其成因, 并针对其风 险来源提出防控措施, 目的在于通过完善相关立法、 建立专业农地评估机构、加快农村信用体系建设、 健全风险补偿机制、加快土地产权信息数据库的建 设等一系列措施降低因土地产权抵押融资风险所带 来的经济损失。相信在不久的将来, 土地产权抵押 融资业务的发展将更上一层楼。

\section{六、参考文献}

[1]财政部财政科学研究所课题组. 城镇化进程中的 地方政府融资研究.经济研究参考,2013,13:3-25.

[2]韩金愮.新兴市场城镇化融资机制建设.中国金 融,2013,16:31-32.

[3]葛扬, 朱七. 论我国城市化进程中土地融资运行 模式.现代城市研究,2013,09:27-30

[4]罗剑朝, 庸晖, 庞筀成. 农地抵押融资运行模式国 际比较及其启示.中国农村经济,2015,03:84-96

[5]张豪仁.农村土地 “双权” 抵押融资的困境及出 路.上海:上海大学,2014 年。

[6]全国人民代表大会常务委员会关于授权国务院 在北京市大兴区等 232 个试点县 (市、区) 、天津 市薊县等 59 个试点县 (市、区) 行政区域分别暂 时调整实施有关法律规定的决定.中华人民共和 国全国人民代表大会常务委员会公报，2016，01： $76-80$.
[7]欧阳国.农村土地承包经营权抵押: 困境与出路. 内蒙古农业大学学报 (社会科学版)，2010，04: 74-76.

[8]杨永富.农村土地承包经营权入股法律问题研究. 长沙: 湖南大学, 2010 年。

[9] 张龙耀, 王梦珺, 刘俊杰.农民土地承包经营权抵 押融资改革分析. 农业经济题,2015,02:70-78+111.

[10]C.F. Huang. Types of credit risks and strategies to improve risk identification by internet of intelligences. Journal of Risk Analysis and Crisis Response.2013,3(1):44-51. 